\title{
THE ROLE OF OXYGEN/NITROGEN BUBBLES IN FLOTATION DEINKING USING A COMMERCIAL SURFACTANT AND THE FATTY ACID OF MORINDA CITRIFOLIA L. \\ TRISMAWATI TRISMAWATI ${ }^{1}$, DARONO WIKANAJI ${ }^{2}$, MUJI SETIYO ${ }^{3}$, CATUR HARSITO $^{4}$, ADITYA RIO PRABOWO ${ }^{5} \&$ ZAINAL ARIFIN $^{6}$ \\ ${ }^{1}$ Department of Industrial Engineering, Universitas Panca Marga, Probolinggo, Indonesia \\ ${ }^{2}$ Laboratory of Nano Bioenergy, Universitas Sebelas Maret, Surakarta, Indonesia \\ 3,4,5,6 Department of Mechanical Engineering, Universitas Sebelas Maret, Surakarta, Indonesia
}

\begin{abstract}
Despite surfactant-based ink removal being extensively investigated, the best quality deinked pulp obtained by flotation deinking exhibits effective residual ink concentration (ERIC) and brightness values that are consistently lower than expected. To understand this, the effect of oxygen and nitrogen bubbling on the behavior of a commercial surfactant and the fatty acid of Morindacitrifolia L. (FAMC) was investigated in this study. Oxidation was found to enable binding between the surfactant / FAMC and the ink components and enhance flotation deinking. The hydrophilic properties of the surfactant also enable the surfactant and FAMC molecules to physically contact or interact with ink components.
\end{abstract}

KEYWORDS: Ink Removal, Commercial Surfactant, Morindacitrifolia L. Fatty Acid\& Flotation Deinking

Received: May 27, 2020; Accepted: Jun 17, 2020; Published: Jun 30, 2020; Paper Id.: IJMPERDJUN2020260

\section{INTRODUCTION}

Flotation deinking using a biodegradable surfactant is among the most favorable processesfor removingdetached ink from fiber surfaces. Ink becomes detachedduring re-pulping,in which shear force dominates along with chemical, enzymatic, and surfactant actions. The detached ink is separated during flotation, which is established by injecting pressurized air into a dilute ink-contaminated fiber suspension, andthe surface tension of water (as the suspension medium) is modified by the addition of a surfaceactive agent (surfactant). The surfactant covers the bubbles that formtheinterface; as a consequence, the bubbles lift the detached ink from the fiber. Although the bubbles have uniform properties, the interactionsbetweenair, oxygen, or nitrogen bubbles, andthe surfactant responsible for detachingtheink are unknown. Accordingly, these interactions were evaluated in this study by investigating their effects on flotation. In this study, the fatty acid of Morindacitrifolia L. (FAMC) and a commercial surfactant (CS) were used as the biodegradable surfactants.

Studies on flotation deinking [1, 2, 3] and microbubble dispersion [4] have been reported. Enzymes are commonly added during the re-pulping step, andenzymaticdeinking has been studied for its overall deinking efficiency $[5,6,7]$. Surfactants are commonly added to the flotation tank, andtheeffect of surfactant adsorption on the hydrophilic solid-water interface has been studied [8]. Relevant to flotation deinking, surfactant behavior has also been investigated and modeled [9]; the separation process in a flotation system has also been simulated[10]andamathematical model for the flotation deinking process has been developed [11]. Studies comparingtheperformance oftheflotation deinking of old newspaper (ONP) using FAMC and CShave been reported $[12,13,14,15]$, withthecommercial surfactant outperforming FAMC, with $2.36 \%$ and $11.70 \%$ differences 
in brightness and effective residual ink concentration (ERIC) values, respectively, reported [12].

Pigments (mostly organic compounds) in ink are formulated with other organic compounds, such as binders, varnishes, and vehicles that mostly contain hydrocarbon chains and are stabilized by the surfactant [16]. On the other hand, hydrophobic ink dyes or pigments in the surfactant solution (above the critical micelle concentration) are solubilizing [17]. Upon dissolution, the surfactant influences specific physical properties of water by decreasing its surface tension, decreasing the mean bubble diameter, and increasing gas hold up and gas movement [18, 19]. Bubbles coalesce differently inapure solvent and aqueous mixtures, with the surface tension less important in the pure liquid than in an aqueous solution, whichistheresult of the specific behavior of the surfactant [18].

Surfactants exhibit different kinetics and equilibrium adsorption behavior at solid-liquid interfaces when mixed with silica, cotton, or cellulose, and show synergism, such as enhancedsurface activity, spreading, foaming, and detergency [8]. The hydrophilic-lipophilic balance (HLB) values of surfactants significantly affect flotation deinking [20, 13, 14]. Surfactants with different hydrocarbon chain lengths perform differently during flotation [21]. Most compounds containing long hydrocarbon chains(such as surfactants and fatty acids) undergo oxidative cross-linking when exposed to oxygen. Cross-linking determines the yield of the flotation process, as interpreted using a model equation that describesparticle removal [22,13]. When alkyd and linseed oil form emulsions, such as in wood-coating formulations [23], they dry when applied to wood surfaces due to oxidative cross-linking promoted by air [24].

In industry, aeration is mostly performed by bubbling air (21\% oxygen and $79 \%$ nitrogen), and innovations that improve flotation performance are always sought after. Oxygen is a reactive molecule that can interact with the double bonds present in unsaturated hydrocarbon molecules through hydrogen bonding, but the same cannot be said for nitrogen. An innovative deinking process using a mixture of ozone $\left(\mathrm{O}_{3}\right)$ and oxygenhas been studied [25]. To reduce the risk of explotion in producing clarified water in oil industry, nitrogen is used instead of air [26]. Oxygen spontaneously reacts with unsaturated fatty acids to produce allylichydroperoxides, dihydroperoxides, and cyclic peroxides [27].

\section{MATERIALS AND METHODS}

A commercial surfactant and FAMC were used in these experiments. To determine which gas has a positive effect on flotation deinking, three gases were used, namely air, oxygen, and nitrogen. Flotation was conducted in a laboratory glass flotation tank and the flotation-deinking results using oxygen, nitrogen, and air were compared. The brightness and ERIC values of the deinked pulp were measured. The results were interpreted theoretically by considering possible interactions between the gas (air, oxygen, and nitrogen) and the surfactant or FAMC that are related to their effects on deinkingflotation.

\subsection{Materials}

The following materials were used: a commercial surfactant (CS; a fatty acid derivative composed mostly of long-chain unsaturated C18:2 hydrocarbons) [manufactured by KAO], FAMC extracted from the seeds of Morindacitrifolia $\mathrm{L}$. (composed mostly of long-chain unsaturated C19:2 octadecanoic acid) [14], sodium lauryl sulfate (SLS) [manufactured by $\mathrm{KAO}$ ], papyrase enzyme [manufactured by $\mathrm{KAO}$ ], ONP [local ONP waste], air, oxygen, and nitrogen [SAMATORIndustrial Gases], and water. 


\subsection{Methods}

The following two steps were used:

The Pulping Step.ONPwastorn into small pieces, and $50 \mathrm{~g}$ of the shredded ONP was disintegrated in $0.9 \mathrm{~L}$ of water for 10 min using a 2000-rpm mixer at $30{ }^{\circ} \mathrm{C}$ and $\mathrm{pH}$ 7. The ONP pulp was poured into a collecting flask. The vessel was rinsed with $0.1 \mathrm{~L}$ of washing water, with the pulp maintained at $5 \%$ consistency [12]. The amount of prepared pulp was sufficient for several flotation experiments.

The Flotation Step.The setup used for flotation in this study is shown in Fig. 1. The pulp sample (500 mL) was mixed with $1 \%$ papyrase enzyme for $10 \mathrm{~min}$ before pouring into a flotation tank filled with $5 \mathrm{~L}$ of water to a consistency of $0.5 \%$ after which $0.15 \% \mathrm{CS}$ and $0.6 \% \mathrm{SLS}$ was added [12]. Flotation was carried out for $10 \mathrm{~min}$ at $\mathrm{pH} 7$ and $30{ }^{\circ} \mathrm{C}$, at oxygen, nitrogen, or air pressures of $1-5 \mathrm{~kg} / \mathrm{cm}^{2}$ through several sizes of orifice $(20,40$, and $60 \mu \mathrm{m})$. The ink-contaminated froth was removed from the upper part of the flotation tank, andthedeinked pulp was drained from the bottom part of the flotation tank and washed over a 48-mesh screen and transformed into a sheet usingahandsheet maker according to the Tappi method (Tappi T 218-om 91). Deinking performance was evaluated in terms of brightness and ERIC using a Technidyne Color Touch 2 ISO instrument [12]. The same experiment was also performed for FAMC instead of the commercial surfactant.

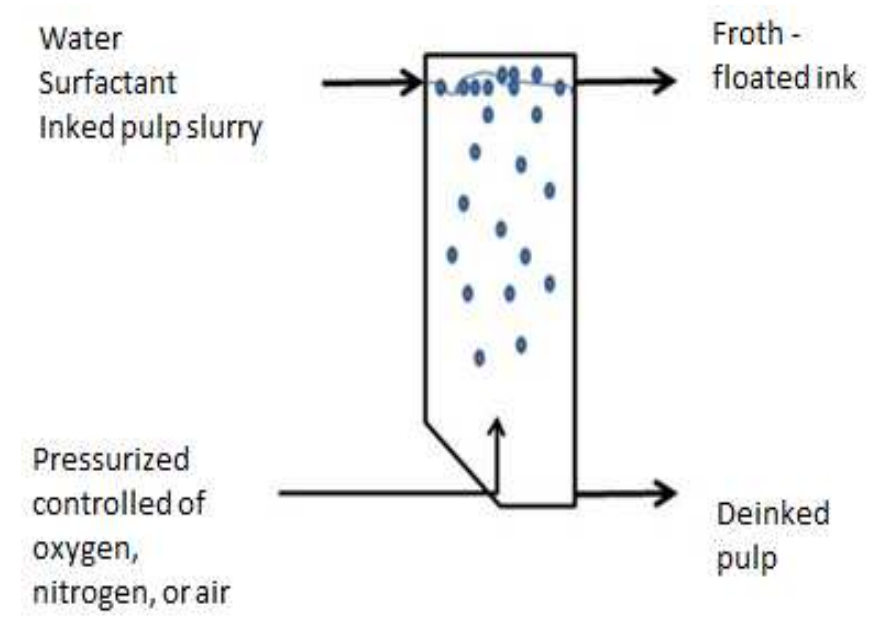

Figure 1: Setup for Flotation-Deinking Experiments.

\section{RESULTS AND DISCUSSIONS}

The commercial surfactant and FAMC were used as surface-active agents to modify the surface tension of the solution during flotation. The fibers and suspended ink-particle solids should be separated by flotation, andflotationwas performed by bubbling oxygen or nitrogengas.Theresults obtained using these two gases were compared with those obtained when flotation was performed by bubbling air, as usedin the standard operating procedure. The performance of the commercial surfactant and FAMC in flotation deinking was analyzed in terms of the brightness and ERIC values of the deinked pulp.

Figure 2 shows that oxygen gas facilitated the best flotation-deinking performance (in terms of brightness) with both CS and FAMC. These results confirm that oxygen, as a reactive gas,improves the surface properties (surface activities) of bubbles covered by either the commercial surfactant or FAMC. On the contrary, nitrogen, as aninertgas,performed most poorly;nitrogenwasunabletofacilitate good flotation deinking performance. 
Figure 3 shows the ERIC values of deinked pulp produced under various conditions. There was less effective residual ink left on the deinked pulp when bubbled with oxygen gas; it seems that more ink particles were removed using oxygen as the bubbling gas. Hence, we conclude that the activities of CS and FAMC are enhanced by oxygen to afford better adsorption properties for ink particles.

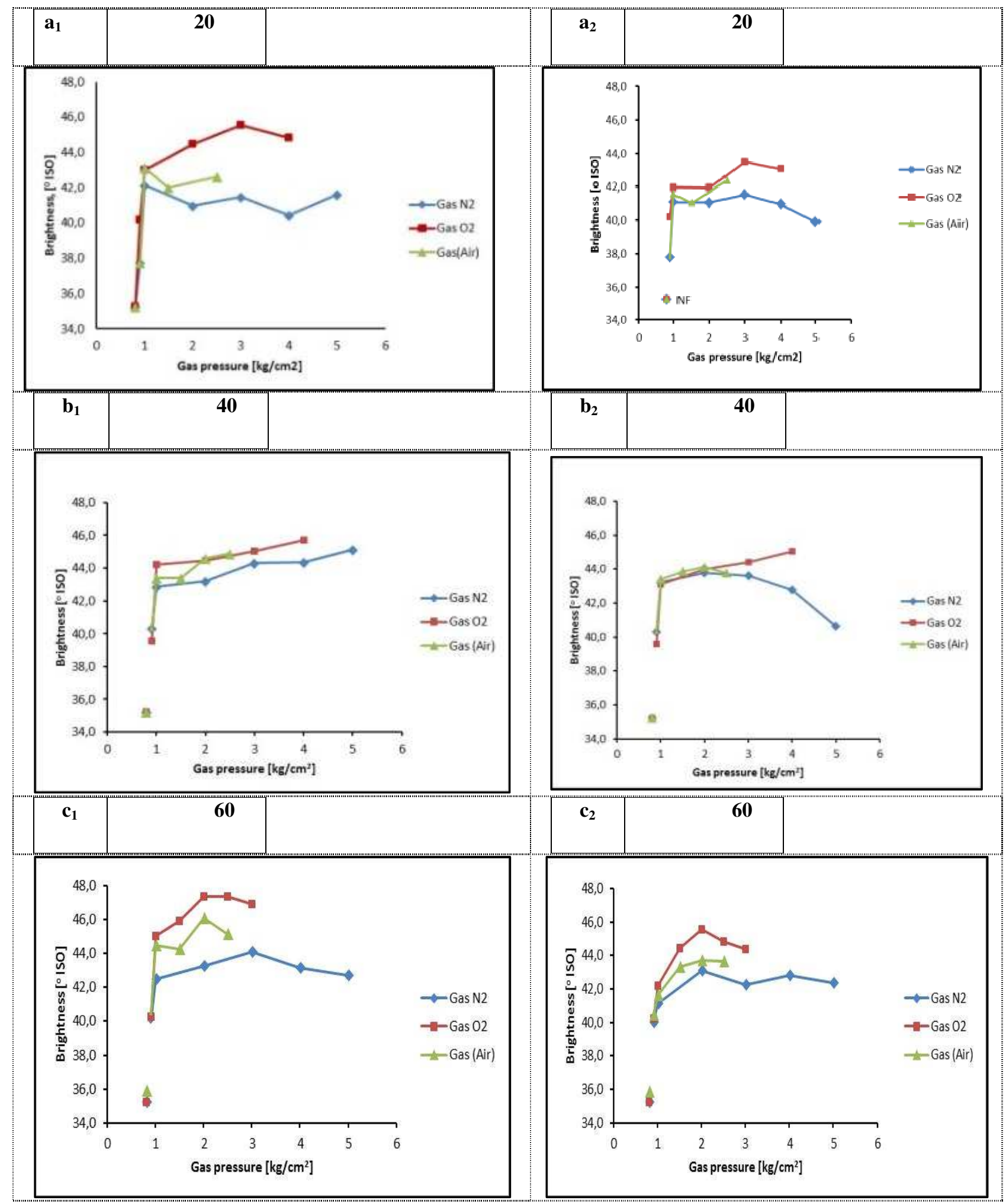

Figure 2: Brightness values obtained using: $\left(a_{1}, b_{1}, c_{1}\right)$ theCommercial Surfactant and $\left(a_{2}, b_{2}, c_{2}\right)$ FAMC as functions ofGas Pressure at variousOrifice Diameters. 

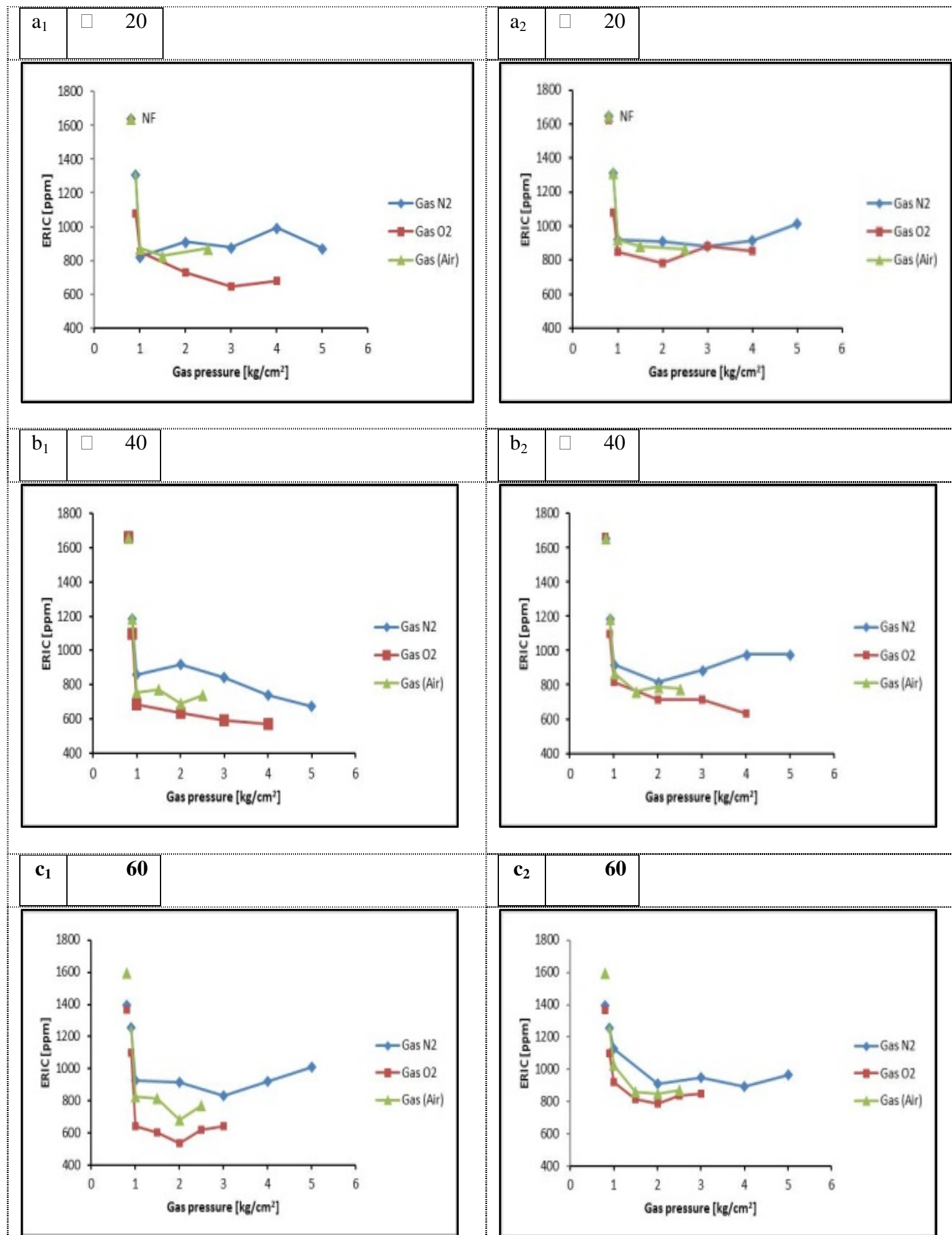

Figure 3:ERIC values obtained using: $\left(a_{1}, b_{1}, c_{1}\right)$ the Commercial Surfactant and $\left(a_{2}, b_{2}, c_{2}\right)$ FAMC as Functions of Gas Pressure at various Orifice Diameters.

As a fatty acid derivative, the CS contains an unsaturated bond in its structure, and FAMC also has an unsaturated bond in its structure. These double bonds, as well as those in ink, appear to be favorable for oxygen attachment as 
illustrated by the interactions shown in Figs. 4 (a, b, and c). These interactions may promote the cross-linkingof both fatty acids with themselves, or with specific components present in the ink particles, in agreement with previous reports [28, 13, 14]. Reactionsbetweenoxygen and unsaturated fatty acidslead to the production of compounds such as allylichydroperoxides, dihydroperoxides, or cyclic peroxides [27]. These interaction products and reaction productsmayimpact the ink-separation process during flotation deinking. As a result, the deinked pulp has higher brightness and lower ERIC values; hence, the effects of these compounds on flotation deinking need to be studied further.

During flotation deinking, phase contact occurs immediately between water (the surfactant solution, in which the surfactant is hydrophilic) and oxygen through liquid and gas contact (two-phase contact) by bubbling (in this case the surfactant concentration should be above its critical micelle concentration (CMC), and between water (the hydrophilic surfactant solution) and the ink (the detached ink particles) through liquid, gas, and solid contact (three-phase contact) during flotation. The interaction probability is less for solid and gas phase contact (ink particles and oxygen) because the ink particles are distributed as detached particles in the water phase and are not in the gas phase. In addition, the ink particles are hydrophobic while the oxygen gas bubbles are covered by the hydrophilic surfactant solution.

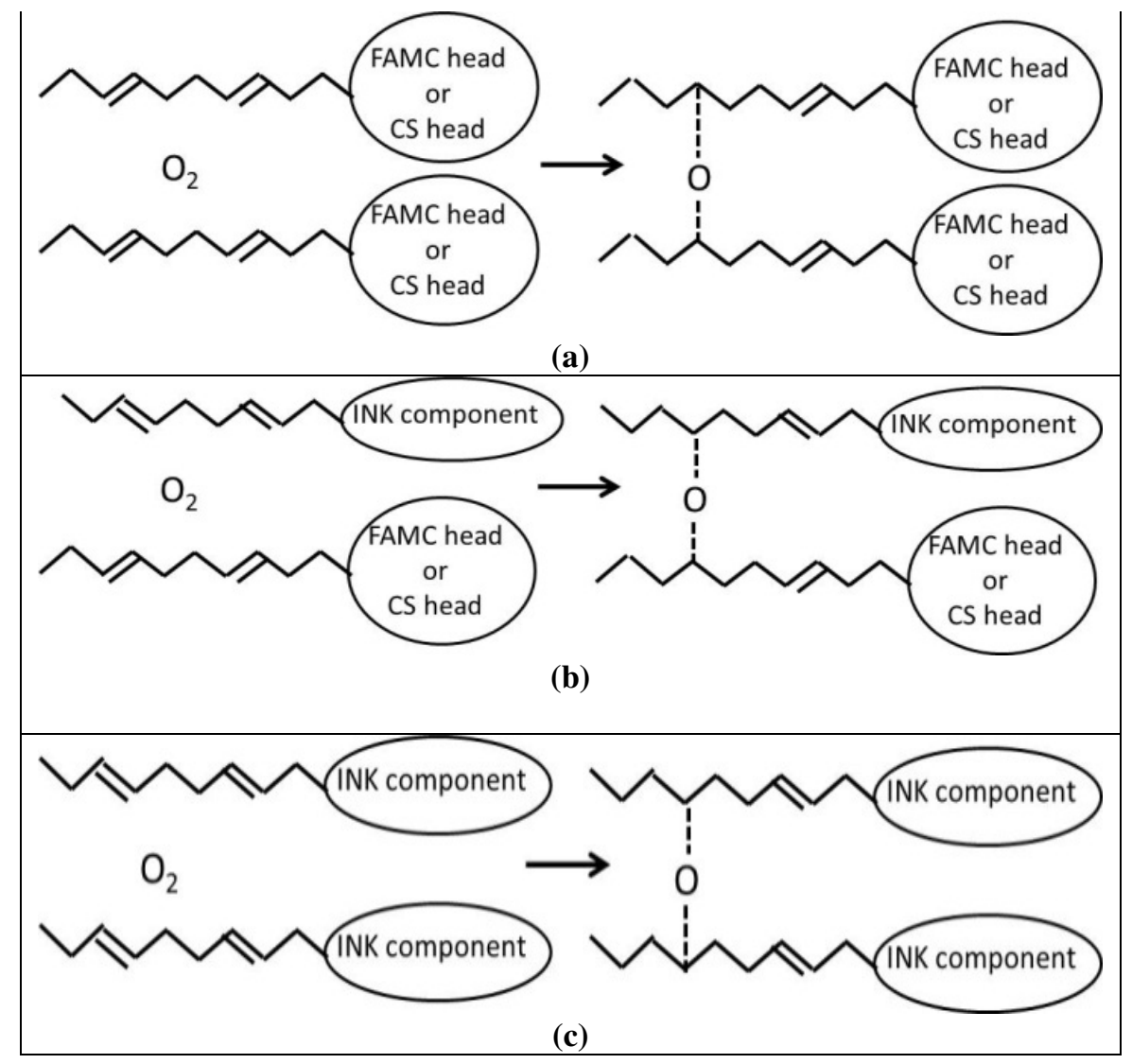

Figure 4: Illustrating possible Interactions between Surfactants (a), between Surfactants and ink, and between ink Components it Selves (c).

FAMC is less effective than the CS when used as an alternative surfactant during flotation deinking. In this case, FAMC is less hydrophilic (HLB value of 5) than the commercial surfactant (HLB value of 13); hence, when it is injected into the water and bubbling is performed, FAMC is distributed as a micro suspension, rather than the solution formed by the commercial surfactant. In the presence of oxygen, the possibility of FAMC molecules interacting with themselves, and FAMC moleculesinteracting with the moleculesintheink particles through hydrogen bonding, as shown in Fig 4 (a and b), 
is lower than that of the commercial surfactant. This is the reason that FAMC performs more poorly than the commercial surfactant.

Bubbles produced from the larger orifice gave better results than those produced from the smaller ones. At the same operating pressure, larger bubble diameters resulted in increased turbulence in the flotation medium, whichresults in hydrodynamic properties more suitable for fiber and ink-particle separation. In this case, oxygen exerts a significantly improved effect than that of nitrogen or air, which is likely related to interactionsbetween oxygen, the surfactant, and some specific ingredients in the printing ink, as discussed above and supported by other research results [27].

The brightness and ERIC values of the deinked pulp treated using the commercial surfactant are superior to those of FAMC (Figs. 2 and 3). It has been noted that a commercial surfactant has special properties that depend on its chemical structure and modifications. Indeed, commercial surfactants with longer hydrocarbon chains provide better flotation results [21]. In the case of the hydrophobic lipophilic balance (HLB) value, an ethoxylated fatty alcohol with an HLB value of 12 afforded deinked ONP pulp with the best properties [28]. The commercial surfactant has a suitable HLB value for flotation deinking, and physically, it is not as oily as FAMC.

\section{CONCLUSIONS}

The effectiveness of oxygen/nitrogen bubbles in flotation deinking using a commercial surfactant and FAMC was investigated. The following observations are made:

- Oxygen oxidizesCS and FAMC, thereby binding the structure of CSor FAMC to itself, ortospecific ink ingredients composed of fatty acids, alkyd resins, or other compounds. This binding is suggested to result in cross-linking with ink particles, which leads to enhanced flotation deinking.

- The best bubbling gas for flotation deinking is oxygen, followed by air and nitrogen.

- The diameters of the bubblesexuded from the $\mathrm{D}_{60}$ orifices exhibit better flotation-deinking performance than thosefromorifices of other diameters.

- Inert nitrogen gas is inferior in flotation deinking.

- The commercial surfactant promotes better flotation deinking than FAMC, which correlates with its hydrophilic properties.

\section{NOMENCLATURE}

$\begin{array}{ll}\text { CS } & \text { commercial surfactant } \\ \text { CMC } & \text { critical micelle concentration } \\ \text { ERIC } & \text { effective residual ink concentration } \\ \text { FAMC } & \text { fatty acid of Morindacitrifolia L. } \\ \text { HLB } & \text { hydrophobic lipophilic balance } \\ \text { ONP } & \text { old newspaper } \\ \text { SLS } & \text { sodium lauryl sulfate } \\ \square & \text { code for the smallest orifice, } 20 \mu \mathrm{m} \\ \square_{40} & \text { code for the medium orifice, } 40 \mu \mathrm{m} \\ \square 60 & \text { code for the largest orifice, } 60 \mu \mathrm{m}\end{array}$

\section{Highlights}

- $\quad$ Biodegradable surfactant is one of the best mediums for flotation deinking to remove detached ink from fiber surfaces. 
- Unknown results is still found on the interactions between air, oxygen or nitrogen bubbles, and the surfactant.

- The interactions were evaluated by considering the fatty acid of Morindacitrifolia L. and a commercial surfactant as the biodegradable surfactants.

- $\quad$ Bubbles exuded from the $\mathrm{D}_{60}$ orifices indicate better performance than other experimental configurations.

- It is explicitly noted that inert nitrogen gas is not effective for flotation deinking process.

\section{REFERENCES}

1. E. Matiolo, F. Testa, J. Yianatos, and J. Rubio, "On the gas dispersion measurements in the collection zone of flotation columns.” Int. J. Mineral Proc.99, 78-83 (2011).

2. Z.I. Emerson, T. Bonometi, G.A. Krishnagopalan, and S.R. Duke, "Visualization of toner ink adsorption at bubble surfaces," TappiJ. 5, 10-16 (2006).

3. SubhashiniVashisth, Chad P.J. Bennington, John R. Grace Richard J. Kerekes, "Column flotation deinking: State of the art and opportunities," Resour.Conserv. andRecycl.55, 1154-1177 (2011).

4. C.A. Costa and J. Rubio, "Deinking flotation: influence of calcium soap and surface-active substances," Miner. Eng., 18, 59-64 (2005).

5. C.K. Lee, I. Darah, and C.O. Ibrahim, "Enzymatic deinking of laser printed office waste papers: Some governing parameters on deinking efficiency,"Bioresour. Technol.98, 1684-1689 (2007).

6. D. Dutt, C.H. Tyagi, R.P. Singh, and A. Kumar, "Effect of enzyme concoctions on fiber surface roughness and deinking efficiency of sorted office paper,"Cellul. Chem. Technol.46, 611-623 (2012).

7. CHEVULA, SREENADH. "DESIGN AND TESTING OF ROCKET MOTORS WITH COMPOSITE PROPELLANTS." International Journal of Mechanical and Production Engineering Research and Development (IJMPERD) 9. 4, Aug 2019, $745-752$

8. A. Singh, R.D. Yadav, A. Kaur, R. Mahajan, "An ecofriendly cost effective enzymatic methodology for deinking of school waste paper,"Bioresour. Technol.120, 322-327 (2012).

9. S. Paria and K.C. Khilar, "A review on experimental studies of surfactant adsorption at the hydrophilic solid-water interface,"Adv.ColloidInterfaceSci.110, 75-79 (2004).

10. Meshram, Atul N., DnRaut, AndSkMahajan. "Factors Affecting The Formation of Gas Porosity In A356 Alloy Wheel By Gravity Die Casting." International Journal Of Metallurgical \& Materials Science And Engineering (Ijmmse) 8. 4, Oct 2018, $1-4$

11. K. Theander, "Studies of surfactant behavior and model surfaces relevant to flotation deinking," Doctoral Thesis, Royal Institute of Technology, 2006.

12. B.-U. Cho, J.-Y. Ryu, and B.-K. Song, "Modeling and simulation of separation process in flotation system,"J. Ind.Eng. Chem.15, 196-201 (2009).

13. F. Bloom and T.J. Heindel, "Mathematical modelling of the flotation deinking process."Math. Comput. Modeling25, 13-58 (1997).

14. Praveen, Jvs, MehboobPathan, and Khalid Ansari. "Hyperbaric pressure testing of a subsea valve to validate deep water condition." International Journal of Mechanical and Production Engineering Research and Development (IJMPERD) ISSN 
(P) (2018): 2249-6890.

15. T. Trismawati, I.N.G. Wardana, N. Hamidi, and M.N. Sasongko, "Characteristic of flotation deinking using bio and synthetic surfactant at different air flow rate," 4th International Conference and Exhibition on Sustainable Energy and Advance Materials, edited by TriyonoAgungTriwijanta (SebelasMaret University Surakarta, 2015), AIP Conference Proceeding 1717, (2015), 11-19.

16. Youssef, G. M., et al. "Investigation of size and band gap distributions of Si nanoparticles from morphology and optical properties of porous silicon layers formed on a textured N+ P silicon solar cell." Int. J. Semicond. Sci. Technol 6 (2016): 1-12.

17. T. Trismawati, I.N.G. Wardana, N. Hamidi, and M.N. Sasongko, "The role of fatty acids functional group in Morindacitrifolia L. on surface tension and diffusion performance into ink particles," TenisdeSurfact. Det., 54, 393-399 (2017).

18. TrismawatiTrismawati, I.N.G. Wardana, N. Hamidi, and M.N. Sasongko, "Seed oil of Morindacitrifolia L. As a surfactant for deinking flotation, "IJChE, 2017,18.

19. Trismawati, I.N.G. Wardana, N. Hamidi, and M.N. Sasongko, "Natural surfactant from fatty acid of Morindacitrifolia L. for deinking flotation, "AJChE, 16, 2, (2016).

20. Joy T. Kunjappu, Ink Chemistry. https://www.chemistryworld.com/news/ink-chemistry/3002158.article

21. A.R.Tehrani-Bagha and K. Holmberg, "Solubilization of hydrophobic dyes in surfactant solutions,"Materials6, 580-608 (2013).

22. H. Chaumat, A.M. Billet, and H. Delmas, "Hydrodynamics and mass transfer in bubble column: Influence of liquid phase surface tension,"Chem. Eng. Sci. 62, 7378-7390 (2007).

23. M. Asari and F. Hormozi, "Effects of surfactant on bubble size distribution and gas hold-up in a bubble column,"Am. JChem. Eng. 1, 50-58 (2013).

24. N. Mayeli and M. Talaeipour, "Effect of different HLB value and enzymatic treatment on the properties of old newspaper deinked pulp,” Bioresour. 5, 2520-2534 (2010).

25. M.A. Abd El-Khalek, "Performance of different surfactants in deiniking flotation process." ElixirAppl. Chem. 46, 8147-8151 (2012).

26. D. Beneventi, J. Allix, E. Zeno, and P. Nortier, "Influence of surfactant concentration on the ink removal selectivity in a laboratory flotation column, "Int. J. Mineral Proc.87, 134-140 (2008).

27. E. Sansonetti, B. Andersons, and I. Andersone, "Novel alkyd-linseed oil emulsion formulations for wood coatings," Baltic Polymer Symposium - IOP Conference Series: Material Science and Engineering 111, 1-5 (2016).

28. P.J. Flory, Principle of Polymer Chemistry, Cornel University Press, Ithaca and London (1953), pp. 106 - 263.

29. Nathalie. Marlin, Filipe Almeida, MarcAurousseau, AlexandreHerisson, and DavideBeneventi, 'Ozoneloxygen reactive flotation for paper deinking," Ozone: Science and Engineering, 35, 381-389 (2013).

30. I. Sandoval-Caballero, "Use of nitrogen in flotation for iron sulfide rejection," Master of Engineering Thesis, Department of Mining and Metallurgical Engineering, McGill University, 1990.

31. F.D. Gunstone, "Reaction of oxygen and unsaturated fatty acids,"J. Am. Oil Chem. Soc. 61, 441-447 (1984). 

